\title{
6. Tuning in: Does TV news influence the political process in Fiji?
}

\section{ABSTIRACII}

Local television news programmes in Fiji have been the most watched programmes for the entire 13-year history of broadcast television in the country. Although survey polls consistently show that television news is extremely popular, the influence it may have due to its popularity has not previously been investigated. This article is based on a study examining the influence that television news programmes have on communities in Fiji. The study shows that the influence of TV news is complex and is interwoven with cultural, economic and political contexts. Findings for the study indicate television news is not only an influential source of information, but that it is also an agenda setter for Fiji public opinion. The research conducted indicates that television news influenced people in Fiji before the 2006 general election. While this influence did not necessarily change the way people voted, it may have helped set the political agenda. Television news may not only be informing the public about forces that shape their lives, but it may be a shaping force itself.

\section{DALE HERMANSON \\ University of the South Pacific}

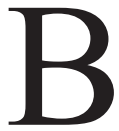

ASED on local audience surveys, television news programmes in Fiji are the most watched programmes on television. They have retained this number one position for the entire 13-year history of broadcast television in the country. Although survey polls consistently show that TV news is extremely popular, the influence that television news may have on the public in Fiji has not previously been investigated. However, a recent study at the University of the South Pacific (USP) in Fiji examined the impact or influence that television news programmes have on communities in Fiji. In 
particular, the study investigated the way that TV news programmes may have affected the public's feelings, their beliefs and possibly even their actions during the two months leading up to the 2006 general elections. The study showed that the influence of TV news was a very complex issue, interwoven with local culture, commercialisation and, of course, politics. The findings of this study were compared with the findings from similar studies done in other, mostly metropolitan, countries. Commonalities emerged, but so did significant differences, owing to the unique cultural, linguistic and ethnic situation of modern Fiji.

\section{Methodology}

The fact that there is only one national free-to-air television service and one primary TV news programme in Fiji during the study helped strengthen the reliability of the data collected. Findings for the USP study indicated that the significant popularity and wide acceptance of television news not only made it an influential source of information, but may have also have established TV news as a powerful agenda setter for public opinion in Fiji. The study examined how public opinion influenced political leaders, particularly in the lead up to the 2006 general election. These leaders were often in positions of power where the decisions they made could directly alter the course of social and economic development in Fiji. By inference then, the study proposed that television news programmes may actually have some influence on social and economic development in Fiji.

Media effects studies are notoriously inconclusive in proving which effects are specifically due to one form of media. This is partly because people do not live in a vacuum with only one source of information. The USP study did not seek to prove a specific effect—such as a voting decision or a policy initiative. Instead, it examined many ways in which television news may be influencing people in Fiji. The results of this research show that television news may actually play a positive role in Fiji's development, but that the news itself is influenced by commercial, cultural and political pressures. The 5 December 2006 military coup in Fiji occurred after the initial research was done for this study. For this reason the findings were not affected by the military takeover, even though the media as a whole has been very much affected since the coup.

A fairly common academic response in media effects studies is to argue 
that studies should be less concerned with 'supposedly measurable effects' and more interested in the various ways in which individuals and groups interpret media messages. According to Allen and Hill (2004, p. 71), these interpretations are potentially more important in understanding how public opinion is influenced by the media than how the media may or may not have influenced the public to take a specific action-such as a voting decision. Instead of tilting the way the public votes, television news may simply define for viewers what the purpose of the election is and focus their attention on specific issues.

The USP study first sought to determine the extent of TV news popularity. This data was drawn from both existing TV audience surveys and original research. The original research included field surveys with 180 households, as well as more indepth qualitative interviews with a small sample of the public, political leaders from three different parties, and several reporters and managers responsible for producing TV news. The field surveys included Fijian and Indo-Fijian household members who had access to television and who were of voting age (aged more than 21). The respondents included an equal number of men and women as well as Fijians and Indo-Fijians.

This study chose as its research period the weeks in April and May 2006 that preceded the 2006 general election in Fiji. It was a time of active campaigning by candidates during which many issues and policies were examined and discussed on news programmes. During an election period, political leaders are usually even more sensitive to the public's perception of them, because that perception might either help them get reelected or get them voted out of their positions of power. Television news may actually influence government policies, because the stories provide voters with politically relevant information.

Through the interviews with political leaders, the study examined the influences of TV news on decision makers. The interviews revealed that these leaders believed that television news programs reflected public opinion. Before Fiji's election, political candidates addressed many political issues that were highlighted on television news. In this way, television news may have played an important role in helping define or even refine the political agenda for the election.

Election candidates need to convince voters that they are addressing issues salient to them. As a potential agenda setter, television news appears to convince some politicians that the issues featured on television news are the 
issues that are important to voters. The result is that issues highlighted on the news become the issues that are addressed during elections and, in turn, may pressure politicians to actually take action to address these issues.

An initial hypothesis for this study was that television news programmes influenced the way people voted in the 2006 Fiji elections. The fact is that the majority of voters in Fiji cast their ballots along racial lines. For the most part, Fijians vote for Fijians and Indo-Fijians vote for Indo-Fijians. Even if people vote along party lines, political parties in Fiji are also ethnically aligned and news programmes would have little effect in changing this strongly ingrained behaviour. Voting in Fiji is also compulsory, so although television news may have had some influence in getting people to vote, it is more likely that people voted because the law required them to do so. Although a small percentage of respondents claimed television news influenced their voting, it was more clear from the study that television news raised voters' awareness of issues during the election.

Qualitative interviews were also done with Fiji Television staff who produce the news. Several of these journalists admitted that political influence in the form of phone calls directly from politicians to Fiji Television's management occurred, although they believed that these attempts were usually resolved by referring politicians to the station's complaints procedures or to more senior management.

According to the news director, their credibility as a news organisation was essential. If the public stopped believing in them as a news service, they might as well stop producing the news. This credibility also needed to be protected, particularly from government meddling, so that television news could survive and carry out its role of socially responsible reporting.

Those interviewed in Fiji Television's news department recognised that there were a number of influences affecting them. One direct form of influence came from the corporate sector, particularly television advertisers. Although Fiji Television tries to maintain a strict division between its news and sales departments, advertisers do not always recognise this distinction. Advertisers sometimes call the news department directly to try to persuade it to run a story promoting a new product, or to 'kill' a story that may portray their service or product in a negative light. According to the news director, these approaches were normally referred to the corporate office.

Corporate influence is potentially a larger threat to the independence and 
credibility of television news than government influence. Interviews with Fiji One News staff indicated that there had been more attempts at influencing the news from corporate sources than from government ones. As a private entity, Fiji TV relies heavily on advertising revenue to survive, and larger advertisers sometimes try to use this vulnerability to their own advantage. One of Fiji Television's major private shareholders is also a board member, the head of a large local company and a major advertiser on television. According to the news department staff, this board member occasionally tried to use his influence to manipulate news stories.

Researchers globally are calling attention to the pervasive role of corporate interests and commerciality in relation to the news media. On one hand, this commerciality of media organisations fuels their growth and ensures their viability in a free market. On the other hand, commercialisation seems intent on maximising profits, often at the expense of the media's social responsibility. Many media organisations throughout the world are fighting a battle against corporate pressure in order to retain their critical public interest role but, according to Deane (2003), 'the evidence is that they are losing'.

Cultural influences also affect journalists, according to those interviewed at Fiji Television. This was partly reflected in the deferential manner in which junior reporters, particularly Fijian reporters, interviewed chiefs and other cultural leaders. To more senior staff, it was clear that these reporters did not pursue as strong a line of questioning as they would have if the interviewee had not been a chief. This could make the interview irrelevant to the story it was intended to augment. This deference to traditional cultural leaders could affect the integrity of a news story.

For indigenous reporters, whose traditional culture was more intact than the mixed race and other ethnic reporters at Fiji Television, there was a dilemma between the demands of modern journalistic styles of reporting and their tradition of respect and allegiance to traditional leaders and cultural ties. Some more unscrupulous politicians and cultural leaders could use this traditional respect as a way of influencing or even quashing a potentially damaging news story, especially among the younger Fijian news reporters.

The influence of culture on news reporters is important. These reporters must make sense of and process news stories about cultural leaders, even if those stories may sometimes be contrary to the respect and silence traditionally shown to these leaders when their indiscretions and questionable activities are revealed. 
Since the December 2006 coup, reporters have also been heavily influenced by the military government. After the overthrow of the elected government, democracy ceased to exist in Fiji. The freedom of Fiji's media since that time has been called into question. The chairman of the Fiji Media Council stated that 'journalists have been intimidated by the military to the point that they do not feel safe to write and publish reports that correctly reflect the true situation' (The Fiji Times, 9 March 2007).

Fiji Television's news editor and other media representatives have been taken to the army barracks for 'questioning' by the military. Some have been taken in more than once. This intimidation may have the effect of creating an atmosphere of 'self censorship' by the media. In this context, the influence of the Fiji media cannot encourage the 'positive' effects that the media could have in encouraging participation in politics, democratisation of political systems and the mobilisation of individuals into participating in national affairs. In fact, the political climate of the post-coup era in Fiji may be creating just the opposite effect.

The household surveys for the USP study involved 180 respondents answering prepared questionnaires. The respondents were drawn equally from urban, peri-urban and rural communities in both the Central and Western Divisions of Fiji. The demographic information was used to qualify and test some of the findings to see if there were variances in response due to ethnicity, income, educational level, gender and/or age.

\section{The findings}

An important part of the household survey examined the choices of news, the frequency with which those surveyed watched the news, viewing habits of the vernacular news updates and qualitative information about their belief and trust in what the news presented. The findings showed that an overwhelming majority of those with access to television watched Fiji One News at least at some time. Most of the respondents watched One National News every day or at least several times a week. The breakdown for these statistics by ethnicity and gender are provided in Table 1.

The majority of the respondents in the USP study chose television news as their primary source of news. These statistics represent a change in values among the Fiji public. In its short 13-year history, Fiji Television's news programmes have usurped the role of daily news providers from the various 


\begin{tabular}{|l|c|c|c|c|}
\hline \multirow{2}{*}{$(\mathrm{n}=180)$} & \multicolumn{2}{|c|}{ Indo-Fijian } & \multicolumn{2}{c|}{ Fijian } \\
\cline { 2 - 5 } & $\begin{array}{c}\text { Male } \\
(47)\end{array}$ & $\begin{array}{c}\text { Female } \\
(43)\end{array}$ & $\begin{array}{c}\text { Male } \\
(44)\end{array}$ & $\begin{array}{c}\text { Female } \\
(46)\end{array}$ \\
\hline Watch TV news & $97.7 \%$ & $97.9 \%$ & $100 \%$ & $100 \%$ \\
\hline Watch TV news every night & $69.8 \%$ & $70.2 \%$ & $78.3 \%$ & $68.2 \%$ \\
\hline $\begin{array}{l}\text { Watch TV as primary source of } \\
\text { news }\end{array}$ & $53.2 \%$ & $48.8 \%$ & $65.2 \%$ & $63.6 \%$ \\
\hline $\begin{array}{l}\text { Watch vernacular TV news } \\
\text { updates }\end{array}$ & $93.0 \%$ & $91.5 \%$ & $91.3 \%$ & $95.5 \%$ \\
\hline
\end{tabular}

newspapers and radio services. This fact potentially gives television news more influence over public opinion and public perception than the other two news mediums, as shown in Graph 1.

One of Fiji TV's audience viewing surveys measured the number of hours of television that viewers watched in a typical week (Tebbutt, 2006). The average number of hours on a daily basis was 1.87 . The data also showed that the total viewing audience before and after Fiji One News reduced dramatically. The household survey for the USP study showed that 90 percent of all respondents watched television news every day or at least several times a week. From this data, it is clear that the majority of the viewing public watched, on average, only one other one hour programme (or two half hour programmes) a day, but otherwise viewers tuned in to watch Fiji One News

\section{Graph 1: Showing primary sources of news}

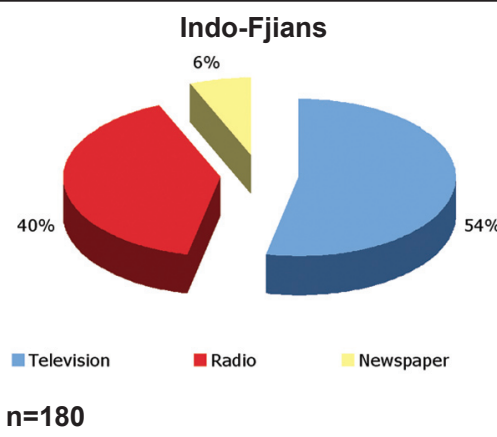

Fjians

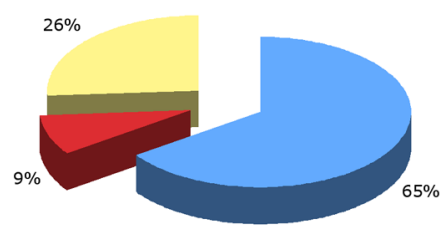


and then tuned out straight afterwards. This correlation may be significant. It indicates that the majority of Fiji's viewing public not only watch the news, but that they watch primarily the news, avoiding most of the more entertainment oriented programmes. This may indicate that the news fulfils some need for the public.

Although a huge percentage of those surveyed watched television news, it is important to understand their perceptions, belief and trust in what they viewed. This measurement of belief and trust helps determine if what they viewed may have influenced their perceptions on election issues and events. Graph 2 shows the levels of belief the respondents had in television news. Interestingly, for both groups 'not at all' was the least popular choice, indicating that at least some level of belief in the news was present in a clear majority of those surveyed.

The questionnaire featured questions that tested whether respondents trusted news presenters and political leaders on the news and trusted news programs in general. A high percentage of all respondents (91 percent) trusted

\section{Graph 2: Showing levels of belief in television news (\%)}

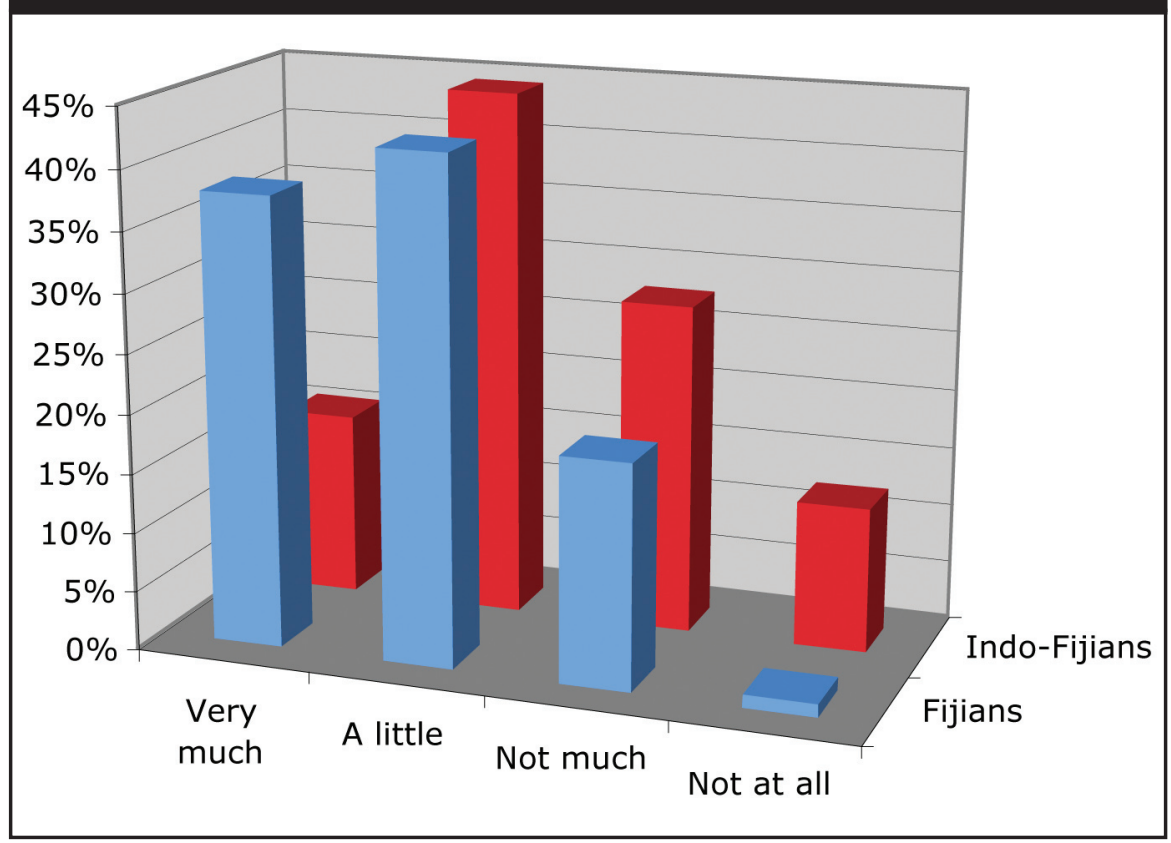


the news presenters at least a little. Trust in political leaders on television dropped to 51 percent however, with only 9.5 percent rating their trust in political leaders on television as 'very much'. These statistics give further indication that viewers believe and trust the news and the news presenters much more than they trust and believe those who actually featured in the news stories, such as politicians. Although the news presenters were merely hired readers for the news service, the audience had a much stronger trust in what they said with their own elected political leaders.

In the USP study, the respondents in the villages and rural areas indicated only slightly higher trust levels than those in the urban areas. Those with less education and less income tended to live in the villages and rural areas. An analysis was done to see how much the education and income levels of these respondents affected their responses on the questionnaire regarding trust and belief. There was only a slight reduction in belief levels among those with tertiary education and higher income. This finding is in stark contrast to an overseas study which indicated that education levels had a more significant influence on belief of the news (Jensen, 1998).

One possible reason for the relative consistency in belief levels among different education levels might be cultural. Fiji viewers would likely have come from more traditional backgrounds than those in the overseas study and might still place more trust in authority figures (including news presenters), and be more accepting of what they are told by these authority figures, even if they have received some tertiary education.

Fiji TV also broadcasts nightly news updates in two of the vernacular languages in Fiji-Fijian and Fiji Hindi. These vernacular updates are translated and summarised versions of the main stories on Fiji One News. The importance of these programmes was reflected by the high percentage of those surveyed who watched these programmes. The vernacular programmes appear every weekday night at 8.15 pm (Khaas Khabre in Fiji Hindi) and 8.45 pm (Ulu ni Tukutuku in Fijian). An overwhelming majority of those surveyed from both ethnic groups watched the vernacular headline programmes $(92.8$ percent) at least some of the time. Although the respondents did not watch the vernacular headlines as often as they watched One National News, these programmes were clearly still very popular.

The result of the responses on viewing frequency for the vernacular headlines highlights the desire for news information to be presented in the 
vernacular languages in Fiji. It became clear during the survey and the indepth interviews that many people relied on the vernacular headline programs to clarify what they had already watched on One National News in English. Their reasoning for watching these programmes appeared to be a higher 'comfort level' with their first language, as opposed to English.

\section{The perceptions}

The USP study also sought to measure the respondents' perception of the cognitive effects television news may have had on them (Graph 3). This is considered a key area of investigation in the study because it helps define some of the effects that viewers themselves perceived television news to have. When asked to describe the effects television news had on them, 66 percent of all respondents felt that news stories informed them, while 25 percent felt that they were educated by news stories. A small percentage (5.5 percent) felt that news stories actually motivated them, but less than 2 percent felt that news stories had no effect at all on them. These results strongly suggest that, at least to the viewers themselves, television news may have played a very significant role in informing and educating them on topics that the news presented.

The questionnaire also sought to establish whether television news stories act as a catalyst for discussion and further transference of information within the household. The questionnaire asked whether respondents discussed the news stories with family and friends. This interaction and subsequent discussion of news stories is important for behavioural change and the democratisation of society, because it helps increase the understanding of the information provided and helps provide a more personal context with which to process that information. According to Robinson and Levy (1986, p. 34), 'interpersonal discussion of news may be at least as powerful a predictor of comprehension as exposure to news media'.

The research shows that 85 percent of both ethnic groups discussed television news programmes at least 'a little' if not 'very much'. This high percentage is significant because it shows that the value of the information transferred through television news does not stop at the viewing stage. The information is discussed, interpreted and carried by viewers and their families. 


\section{Fijians}

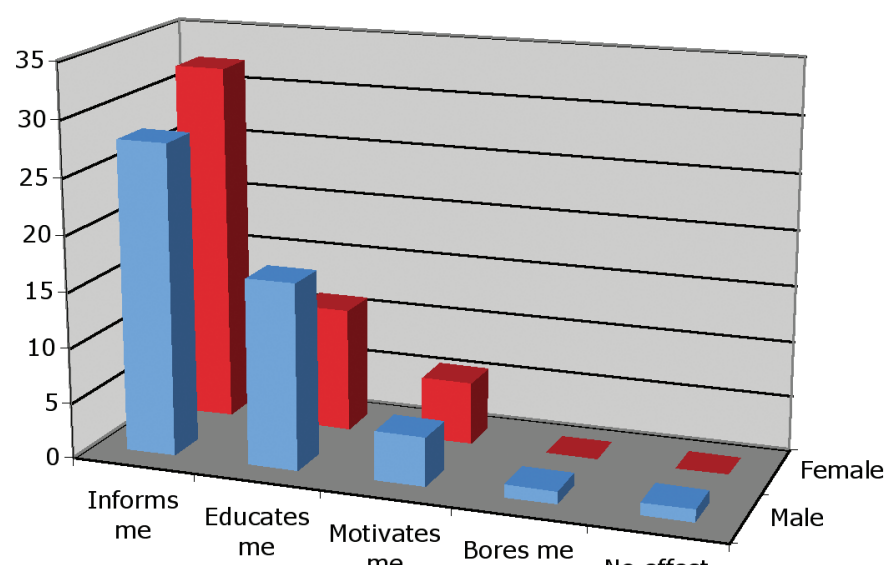

\section{Indo-Fijians}

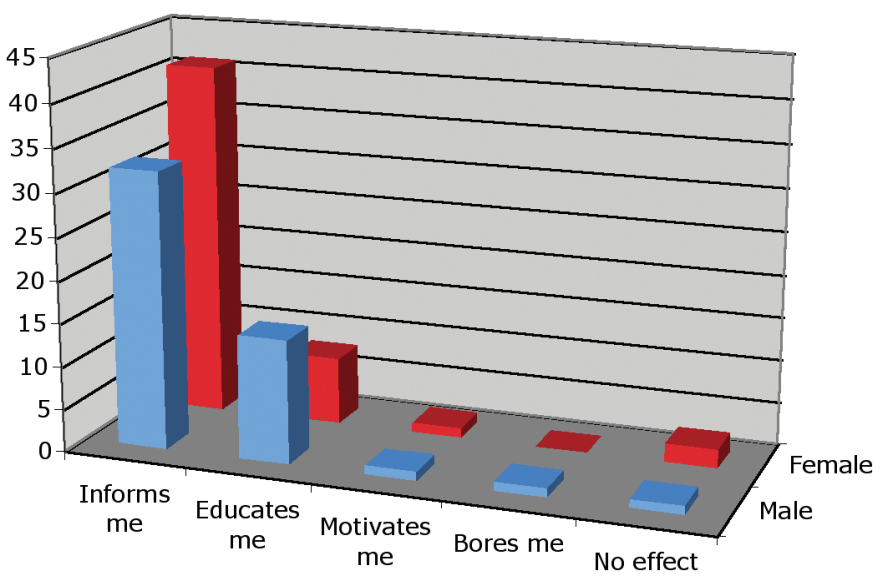

$n=180$ 


\section{The public view}

The USP study also included 12 members of the general public who were interviewed in a more in-depth manner. These indepth interviews were conducted amongst people from urban, peri-urban and rural areas. The main questions asked were why they watched television news, their viewing habits during the research period, their perception of the value of television news, their memory of television news stories from the previous evening and their perception of the benefits of watching television news.

The primary reason given by most of the interviewees for watching TV news was to stay informed, to know 'what's going on'. Nearly all of those interviewed watched television news every night or at least several times a week. During the election period, nearly all of those interviewed admitted watching the news even more closely than usual as the various candidates were paraded onto the screen and the party platforms were highlighted. Most of those interviewed felt that the news reports before the election better prepared them for the actual voting. A majority of the indepth interviewees felt that the news stories may have influenced their voting in some way, although they did not feel that the news stories helped determine their choice of a candidate. Both of these results indicate that television news may exert some influence in the election process.

The 'value' of watching television news was the next primary question asked of the interviewees. Nearly all of those interviewed felt that the main value of television news was informational or educational in nature. The interviewees were asked about their reaction to stories of accidents and crime stories in the news. They commented that they felt crime and accidents were increasing at an alarming rate. This reaction is indicative of 'cultivation theory', which holds that after repeated exposure to stories of abnormal events, viewers begin to see these events as 'normal' even if actual statistics show that crime and accidents are not increasing (Gerbner et al, 1978).

The indepth interviews with the general public revealed certain 'trends' in the substance of their responses. Many of those interviewed had watched television news regularly since it began in 1995 . When asked about any perceived long-term effects from watching television news, some of the interviewees felt that they were better informed on the events happening in the country and felt frustrated about recurring news items that seemed unresolved such as poor road conditions and water supply problems. Most felt satisfied with 
the informative role that television news played. Many of those interviewed however felt that they were unable to individually act to change or respond to anything they saw on the news. Although the stories generated concern in their minds, they did not necessarily feel empowered to do something about the causes of those concerns.

Those interviewed primarily described the positive benefits of television news viewing, mainly the educational and informational value of watching the news. Even those who related negative comments still watched television news regularly. This may imply that, although television news viewing can sometimes elicit negative responses, viewers continued to watch because the positive values of watching outweighed the negative values. Of course, it may also simply imply that, as a learned habit, viewers are reluctant to stop watching because habits are difficult to break.

There was some consistency in the indepth responses to the trustworthiness and believability of television news. There seemed to be a widespread feeling that 'if something is on television news, it must be true'. Why else would it have been broadcast? This belief in the 'truthfulness' of television news stories elevates the value of those stories in the minds of the viewers. Television news appeared to be the supreme authority on what was and wasn't happening in the community. In this way, television news was helping to 'set the agenda' for what was important in Fiji and was able to increase or decrease that importance through the frequency of news stories about that topic.

The exclusion of issues also helps in setting the social and political agenda in Fiji, by focusing attention on certain issues and ignoring others. Television news, in this agenda-setting role, appeared to greatly influence the opinions of those interviewed, homogenising their views on particular issues that the news had covered in its stories. In contrast, when asked about issues such as child rights, specific labour disputes or other topical issues that had not been on One National News, those interviewed had a distinct lack of knowledge and, because of that, no opinion on these issues. As stated before, the role of television news as an agenda setter for the election is significant because it helps determine what are 'important' issues and ignores issues that, for the television news at least, were perceived as being 'not important'.

When asked how television news affected them during the lead-up to voting, several of those interviewed remarked how the news coverage made them more interested in the election. This interest was due to an increase in 
knowledge about some of the candidates, a better appreciation for some of the issues the politicians discussed and a better understanding of the election process itself. According to the interviewees, the questions that reporters put to candidates during news stories were the same questions that they would have wanted to ask. One interviewee remarked that television news in some way 'acted on their behalf' by providing information and getting to the 'truth' of an issue or news story.

Several of the interviewees felt that the primary value of television news in the election period was its role in 'clarifying' what was happening in the buildup to the election. The respondents' feeling that television news increased their understanding of the issues may be a significant finding. Although no measurement was used to test if they really did understand the issues better, their personal perception was important. It indicated that they felt that the information provided in news stories was relevant and useful to them for voting in the election.

\section{The view of the politicians}

All three of those politicians interviewed for the study watched One National News on a very regular basis. Their reasons for doing so were similar to that of the general public: they wanted to feel informed and they relied on television news to stay abreast of national happenings. Unlike the general public though, these politicians described how they would take special note of issues that they could address politically. In this way, television news was establishing an agenda for these politicians, informing them about social and economic issues that they could then try to address through speeches, statements and possibly even policy changes.

One politician that was interviewed was noted for being accessible to the media at nearly any hour of the day, except during the One National News broadcast. Phone calls from reporters during this hour were simply not answered, or callers were told to call back after $7 \mathrm{pm}$, when the news finished. This implied that the television news stories were of such importance to that politician that they would withhold an interview or comment until after they had seen and heard what had been said on television news.

Despite their reliance on television news for information, the politicians interviewed had a decidedly jaded view of the 'truthfulness' of One National News. According to interviewees, corrections and retractions to news errors 
were not always made. Another example that one politician related was the habit of reporters to 'skew' a story by making it appear that an attempt had been made to balance the story by getting an alternate viewpoint to the first interview.

As an example, a reporter would record an interview with one politician but not seek to get the opposing politician's views. However, the reporter would announce that 'an attempt was made to reach them for comment'. To unsophisticated audiences this could imply that the opposing politician was hiding from the question, and could result in a one-sided news story. To the politician interviewed for this study, they saw it as a way for the reporter to provide the story with the perspective they wanted, but pretend that an attempt had been made to balance it.

An interview with one political leader revealed that at least one political party actually dropped some of its candidates based on their inability to come across well on television. An overseas political consultant reportedly recommended that certain candidates should not be considered for the 2006 election. Some of these candidates were seen on television to appear listless and indifferent during previous sittings of Parliament. They were subsequently dropped from the list of candidates for the 2006 General Election. If this is true, it indicates clear influence on the political process by television news programs, in this case actually influencing the choices of candidates due to concern about how the general public might perceive them as a candidate standing for election.

Politicians interviewed for this study described their reliance on television news as a gauge of issues important to the public. They even admitted being influenced by issues that were raised in news stories--especially those that highlighted concerns in the community. Those interviewed admitted that public opinion heavily influenced them. They determined what 'public opinion' was through stories on television news, letters to the editor in the daily newspapers, commentary on radio stations and through conversations with average people in the community.

It is significant that these politicians, who held elected positions in government, used television news as one of their primary gauges of what people in the community thought and what the community wanted. By further admitting that public opinion influenced their decisions on policies, and their attitude on 'what needs to be done', this indicates that television news may 
have some indirect influence on government policies and political agendas. This demonstrates considerable impact on the community.

Another political leader interviewed revealed that television news stories had even been debated in Parliament. One Member of Parliament had addressed a parliamentary session on a particular issue and, in their address, referred to a television news story as 'proof' of what they were claiming. According to this leader, news stories were also commonly discussed around the corridors of Parliament, which indicated to him how influential news stories were on sitting parliamentarians. A study conducted at Cambridge (Suphachalasai, 2005) highlighted the relationship between environmental issues that were featured on television news and the changes in policies and mandates of politicians. That study showed that some issues on television news were influenced by public opinion and they in turn further influenced public opinion. Politicians who supported the public's environmental positions tended to be re-elected. This led to a model that demonstrated that television news had an indirect impact on government policies. The statements by politicians interviewed for the USP study seemed to support this model but also showed that politicians influenced public opinion as well as being influenced by it. This demonstrates an interactive relationship between politicians, television news and the general public, rather than a one way direction of influence.

\section{Conclusion}

Based on the original research conducted for the USP study, television news does influence people in Fiji, but this influence does not necessarily result in a measurable action by the public. The influence appears to be a gradual change in perspective and perception on issues and events that are reported on television news. In doing so, television news fulfils a basic human right to information as well as feeds the public's desire to know more about the forces that shape their lives.

The USP study's findings indicate that television news influences and may even generate public opinion. This is due to the consistent popularity of TV news and the belief and trust with which most viewers watch it. The findings also indicate that public opinion can influence political leaders who may take action as a result of public opinion, or at least claim that they will take action to address public opinion issues. 
The missing element in this communication model is the public's reciprocal influence on television news. Apart from telephone calls to the TV station, viewers have little opportunity to influence the news or the way in which news is portrayed. The information provided on TV news is primarily a one-way conduit, inundating viewers with images and sounds that have been pre-packaged by Fiji Television. This 'package' appears to be heavily influenced by corporate, political and cultural forces, but as long as TV news maintains an image of integrity with the public, viewers will continue to trust and believe the news. If that integrity is regularly called into question though, by the public and not simply by politicians, then television news' influence may diminish. Until that day comes, television news should continue to enjoy a highly influential role in the politics of Fiji.

\section{References}

Allen, R. C and Hill, A. (Eds.) (2004). The television studies reader. London: Routledge.

Barker, C. (1999). Television, globalisation and cultural identities. Philadelphia: Open University Press.

Deane, J. (2003). Communicating in the information society. Geneva: United Nations Research Institute for Social Development.

Fiji Times, The, (2007, March 9). Suva.

Gerbner, G., Gross, L., Jackson-Beeck, M., Jeffries-Fox, S., \& Signorielli, N. (1978). Cultural indicators: violence, profile no. 9. Journal of Communication, 28: 176-207.

Jensen, K. B. (Ed.) (1998). News of the world: world cultures look at television news. London: Routledge.

Robinson, J. P and Levy, M. R (1986). The main source: learning from television news. Beverly Hills: Sage Publications.

Suphachalasai, S. (2005). Development, environmental policy, and mass media: theory and evidence. London: Department of Land Economy, University of Cambridge. Tebbutt Television Audience Research Report, Tebbutt Research (2006). Suva.

Dale Hermanson is general manager of Pasifika Communications, a media production company in Fiji. He has spent the past 22 years in Fiji working in media training and production. This article is based on research conducted for his thesis for a Masters in Development Studies degree at the University of the South Pacific. The thesis title is 'Tuning In: The Impact of Television News on Fiji Communities'.

dale@pasifika.com 
Copyright of Pacific Journalism Review is the property of Auckland University of Technology and its content may not be copied or emailed to multiple sites or posted to a listserv without the copyright holder's express written permission. However, users may print, download, or email articles for individual use. http://www.aut.ac.nz/depts/commstud/journ/pjrsubs.shtml 